\title{
CLINICAL AND RADIOGRAPHIC EVALUATION OF RECONSTRUCTION AND PROSTHETIC REHABILITATION OF MANDIBULAR RESECTION DEFECTS USING ILIAC GRAFTS COMBINED WITH IMPLANT PLACEMENT
}

\author{
Abdullah A. Hammuda* and Iman A. El-Asfahani **
}

\begin{abstract}
The aim of the current study was to evaluate efficacy of using iliac grafts combined with implants and retaining a provisional fixed-detachable (hybrid) prosthesis in the reconstruction of mandibular defects regarding average bone loss in graft height, peri-implant marginal bone loss, maximum bite force, facial asymmetry ,patient satisfaction and oral health quality of life (OHRQoL).
\end{abstract}

Patients and methods: 11 patients were subjected to mandibular marginal resection with immediate reconstruction by autogenous iliac crest graft with implant placement. After 6 months they were rehabilitated with provisional screw-retained prosthesis. Radiographic assessment of average bone loss in graft height and marginal bone loss around dental implants was performed. Facial asymmetry, Maximum bite force, Patient satisfaction and oral health quality of life (OHRQoL) were assessed after the first surgery, at loading, 6 and 12 months later.

Results: Average bone loss of graft height (mean 2.14 \pm 1.03 ). Average peri-implant Marginal bone loss after 1 year $1.42 \pm 0.38$. The increase in marginal bone loss along the study period was significant $(\mathrm{P}<0.001)$. Maximum bite force of the rehabilitated side increased significantly along the study period. There was a statistically high significant difference between the scores of all OHIP-5 items scores except in the scores of the difficulty doing usual jobs item.

Conclusion: Within the limitations of this study, it was concluded that construction of mandibular defect using iliac crest graft combined with dental implants and retaining a provisional fixed- detachable prothesis can be an effective procedure to restore bony defect, facial asymmetry, maximum bite force, patient satisfaction and oral health quality of life.

KEY WORDS: Mandibulectomy, mandibular defect, iliac crest, non-vascularized graft, maximum bite force, dental implants, marginal bone loss, and patient satisfaction

* Lecturer of Oral and Maxillofacial Surgery, Faculty of Dentistry, Minia university

** Lecturer of Removable Prosthodontics, Faculty of Dentistry, Minia University 


\section{INTRODUCTION}

Mandibular defects may occur due to several reasons such as pathological lesions congenital anomalies, trauma or iatrogenic. Mandibular defects following tumor resection either segmental mandibulectomies, marginal or rim mandibulectomies result in a severe mandibular continuity defects often affect both form and function that can significantly diminish quality of life. A multidisciplinary approach is demanded to improve functional and cosmetic consequence. ${ }^{1,2}$

Mandibular defects can be divided into defects involving the anterior mandible, lateral mandible, and ramus/condyle. Marginal or non-segmental mandibulectomy can be defined as any excision of a mandibular portion (commonly the alveolus), leaving the continuity of mandibular arch intact. ${ }^{3}$

Autogenous bone is thought to be the "gold standard" graft procedures for reconstruction of mandibular defects. Using free vascularized tissue grafts; fibula, iliac crest, radial forearm, and scapula has become a reliable procedure in recent years because the potential for good functional and esthetic outcomes. A vascularized free osseous graft over the past 30 years became a reliable mandibular reconstruction procedure with success rates of over $90 \%$. It was recommended in compromised irradiated tissue, and the primary placement of the implants. ${ }^{4,5}$

Non-vascularized bone grafts from iliac crest is another option for reconstruction of lateral mandibular defects. It has several advantages, such as low donor morbidity, consistent shape, a suitable volume, better bone quality and quantity. This type of bone reconstruction provides bone continuity, adequate facial contour, and adequate support for the implant placement and implant supported prosthetic rehabilitations. They are associated with a high rate of complications and are prone to osteoradionecrosis after radiation therapy. ${ }^{6,7}$
There is no other free tissue transfer can achieve the same degree of vertical height augmentation and quality of bone achieved by the iliac bone graft. It is ideal graft for mandibular reconstruction, particularly when osseointegrated implants are considered. However, the morbidity associated with the iliac crest harvest limits its popularity. ${ }^{8-10}$

Implants can be placed at the time of the primary reconstruction or delayed after graft healing. The shortening of treatment times without jeopardizing the long-term survival of dental implants provides a significant benefit for patients, especially those suffering from maxillofacial lesions will be subjected to surgical resection causing a mandibular defect compromising mandibular support and function , where longer waiting times may determine a significant discomfort, due to prosthesis instability. Depending on the conditions and anticipated prosthetic rehabilitation, the reconstruction can be performed parallel to the resection or as a separate procedure. The reconstruction procedure target that should be considered is to restore the continuity of removed tissues followed by the rehabilitation of the stomatognathic system. The reconstruction of the mandibular bone continuity is related to the prosthetic treatment .The mastication in patients with and without reconstruction of the mandibular bone continuity evidently show that the oral function is much better in the patients after reconstruction. ${ }^{11}$

Early placement of implants avoids the need for a second surgery, enhancing dental rehabilitation in regard to time and social adjustment. In general, it is convenient for patients with benign lesions or lowgrade malignant tumors with excellent prognosis. Nevertheless, delayed placement of osseointegrated implants is favored by others, who suggest that blood supply of the bone flap at the primary surgery may be compromised because of osteotomies and hardware placement, and also that placement of implants is less precise at the first surgery, as healing of the soft tissues and bone has not yet occurred. Also, in patients with an unknown prognosis, it may 
not be appropriate to place implants primarily. ${ }^{11-13}$

Prosthetic rehabilitation of mandibular defect cases involves the restoration and preservation of oral functions, esthetics, comfort and health of the patient by the replacing of lost teeth and adjoining oral tissues with artificial prothesis. Implant retained prosthesis in patients with mandibulectomies are crucial to enhance stability, retention and support outcomes leading to improved speech and function. ${ }^{14,15}$ Prosthetic treatment options include fixed implant-retained prosthesis and removable partial denture. ${ }^{16}$ Nevertheless, fixed implant-retained prosthesis is not always possible, especially in patients with extensive residual ridge resorption and mandibular defects due to trauma and/or surgical ablation of tumors. In these cases, the prosthodontist might resort to an alternative treatment modality, to reestablish the missing soft and tissues and provide better esthetics, hygiene, phonetics and comfort. This treatment option is the fixed-detachable' prosthesis (hybrid prosthesis) which achieves the objectives of the rehabilitation such as support, stability, and retention characteristics of a fixed prosthesis in addition to esthetics and hygiene maintenance of a removable prosthesis. ${ }^{17}$ It provides an affordable treatment option satisfying patient's esthetic demands together with providing a good prognosis and conservation of the remaining oral structures. In certain clinical situations, hybrid (screw-retained) prosthesis may be preferred, especially in cases with increased inter-arch distance, restricted financial resources and decreased need for soft tissue support. ${ }^{18,19}$

Defects in the mandible following resection cause facial asymmetry and disharmony, as well as malocclusion and tooth loss compromising chewing and lip support. In addition, the mandible also plays a major role in airway protection and support of the tongue, lower dentition, and the muscles of the floor of the mouth permitting mastication, articulation, deglutition, and respiration. Oral health impact profile (OHIP) is the most widely used validated instrument to measure Oral Health-Related Quality of Life (OHRQoL). The OHIP is usually used to evaluate the impact of oral disease on quality of life and to measure the outcomes of clinical interventions in regards to patient look perception. ${ }^{20}$

Few studies have evaluated postoperative outcomes and oral health quality of life of patients rehabilitated with implants retained fixeddetachable prostheses for mandibular reconstruction with iliac grafts. There is also a lack of objective and subjective evidence of this treatment modality on the masticatory efficiency and bite force of patients. A chief indicator of the functional state of the masticatory system is the generated biting force. The ability to bite is controlled by craniomandibular structures, including the muscles of mastication and the dentition, whether it is it natural or artificial. ${ }^{21}$

The aim of the current study was to evaluate efficacy of using iliac grafts combined with implants and retaining a provisional fixed-detachable (hybrid) prostheses in reconstruction of mandibular defects on average bone loss in graft height, peri-implant marginal bone loss, facial asymmetry, maximum bite force, patient satisfaction and oral health quality of life (OHRQoL).

\section{PATIENTS AND METHODS}

In Oral and Maxillofacial surgery department at faculty of dentistry, Minia university. Eleven patients were selected in 2015 and 2016 for the current study as they subjected to mandibular marginal resection with immediate reconstruction by autogenous iliac crest graft with implant placement. All patient selected in the current study presented with unilateral benign lesions that didn't invade the inferior margin. They were selected with their health condition fit to withstand the surgical procedure and postoperative recovery period. Patients presented with carcinogenic tumors or marginal defects were excluded from the study. Patient with systemic diseases or history of smoking were also excluded. 
Preoperative radiographic evaluation by computed tomography CT and panorama. Biopsy was performed for all cases before deciding the treatment plan. All patients signed an informed consent before surgery. (Figure 1)

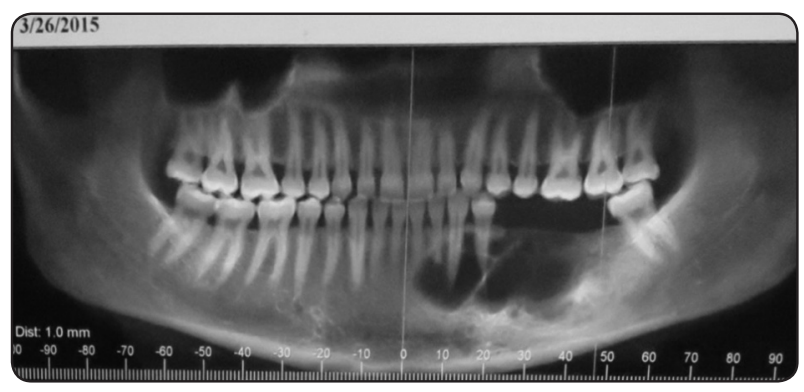

Fig. (1) Preoperative Panoramic x-ray implants (mm) .

Surgical stage: The surgical procedures were performed included marginal resection combined with reconstruction by iliac crest grafting and insertion of dental implants. All cases were operated under general anesthesia through intraoral approach. Patient and surgical field was prepared then reconstructive plate 2.3 (O\&M medical $\mathrm{GmbH}$, Herrnburg -Germany) was adapted on the lateral side of the mandible. Vestibular mucoperiosteum incision and total exposure of the lesion was performed. Borders of the osteotomy were marked with holes by round bur then connected with fissure surgical bur to create a clean-cut segmental osteotomy. Periosteum surrounded the lesion was removed.

Harvesting of iliac crest graft was taken from anterior iliac crest and prepared by multiple cortical perforations before fixation and in cases with large defect the graft was splitted and adapted to the defect and fixed with screws to the reconstruction plate. In three cases with large defects the graft was obtained from both sides. Drilling holes in the cortical part of iliac crest before implant placement was undergone in some situations
Dental implants were placed into the grafted bone following stabilization of the graft (Frontier ${ }^{\circledR}$ implants manufactured by ilerimplant, Spain). Implants were inserted aiming to achieve acceptable initial stability minimum $25 \mathrm{~N} / \mathrm{cm}$ (Newton Per Centimeter) and anchorage in the remaining basal bone. Bone condensing was a used to enhance the bone density around the implants and stability when the condition of bone density in the implant recipient site was not ideal. Normally all implants were covered with cover screws however deeply inserted implants were covered with healing cap to facilitate later exposure of implants at loading stage.

The surgical wound site was primarily closed by direct suturing of the oral mucosa. Advancement of buccal mucosa was performed to cover implants and graft. Antibiotics, anti-inflammatories and analgesics were administered during the hospitalization and mouthwash with Betadine ${ }^{\circledR}$ $1 \%$ was used as an adjunct to oral hygiene. The patients were discharged 1-3 days after surgery and remained using antibiotics and analgesics for seven days. (Figure 2 and 3)

After 6 months a second stage surgery aimed to expose the dental implants and attachment of multiesthetic abutment $\mathrm{ME}$ as it was tightened under $30 \mathrm{~N} / \mathrm{cm}$ and covered with ME healing cap. Five cases from eleven were subjected for this stage under general anesthesia as well as the reconstructive plates were removed.

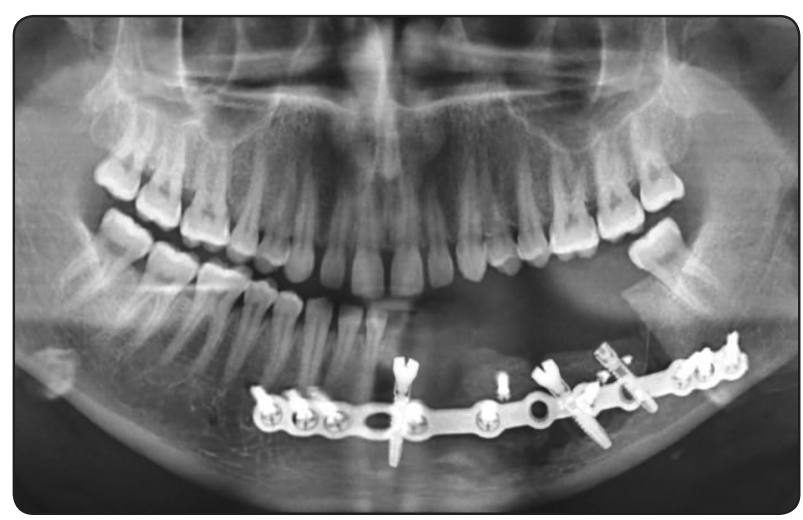

Fig. (2) Postoperative Panoramic x-ray 


\section{Prosthetic stage}

Primary impressions of the maxillary and mandibular arches were made with irreversible hydrocolloid impression material (Cavex CA37, Normal Set, Holland) material. Diagnostic casts were poured and special self-cured acrylic resin trays (Acrostone, Cold Cure, Acrostone dental factory, Egypt) were constructed on them. Diagnostic cast were mounted on semi- adjustable articulator (Hanau Wide View; Whip Mix Corp., Louisville, KY) with the help of facebow record and preliminary jaw relation registration to evaluate inter-arch distance and existing occlusion. Secondary impressions were made using rubber base impression material (Aquasil Easy, Dentsply, York, PA). Master casts were poured in dental stone (Hard type III gypsum, Zeta dent, Italy). They were Mounted on semiadjustable articulator was done using facebow record for maxillary cast and centric relation record for the mandibular cast. Provisional acrylic resin partial denture was fabricated from heat- cured acrylic resin (Dentsply, 570 West College Avenue York, PA 17405. USA). The provisional prosthesis was designed to be screw-retained to implants placed in the iliac bone graft to facilitate adequate hygienic maintenance. Access Holes were created in the fitting surface of the provisional prothesis in the places of the implants' abutments. Titanium cylinders were screwed to implants' abutments and the prosthesis was inserted with the holes around titanium cylinders to ensure complete seating of the prosthesis without interference. Self-cured acrylic resin was placed in the holes to pick up the titanium cylinders and fix them to the prosthesis.

The complete seating of the denture in the patient's mouth was checked while the acrylic resin set. The titanium cylinders were then screwed out, and the denture was removed from the patient's mouth once the cylinders were completely attached. Excess acrylic resin was removed then the prosthesis was returned to the patient's mouth, seated in the final position, checked for occlusion and necessary adjustments were made. The prosthetic appliance screws were fitted under $15 \mathrm{~N} /$ $\mathrm{cm}$. The screw access holes were sealed using guttapercha prior to composite fillings to seal the screw hole in the prosthesis. Following the delivery of the provisional fixed-detachable prosthesis, patients were given oral hygiene instructions and placed on recall maintenance programs every 6 months. Every 6 months in the follow up visits, the prosthesis was retrieved from the patient's mouth by removing the composite fillings, exposing and unscrewing the screws. Oral hygiene measures were done then the prosthesis was seated in position and screws were tightened and access holes were sealed (figure 4 a, b, c)

\section{Evaluation parameters:}

1. Average bone loss in graft height: It was measured on Panoramic x ray after first stage surgery and before implant insertion.

2. Marginal bone loss around dental implants: Average mesial and distal marginal bone loss was
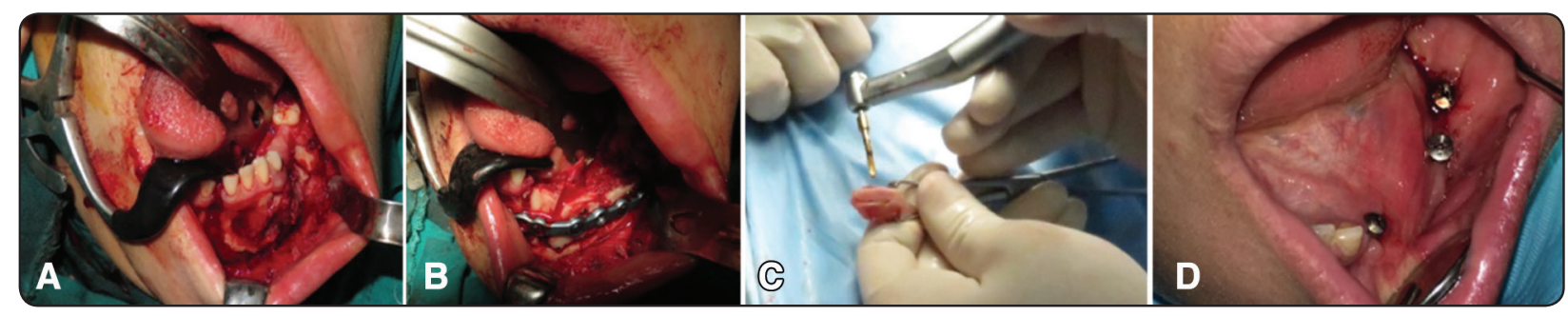

Fig. (3) a: resection of the lesion, b: fixation of the iliac graft c: preparation for implant in the graft d: postoperative clinical photography after healing 


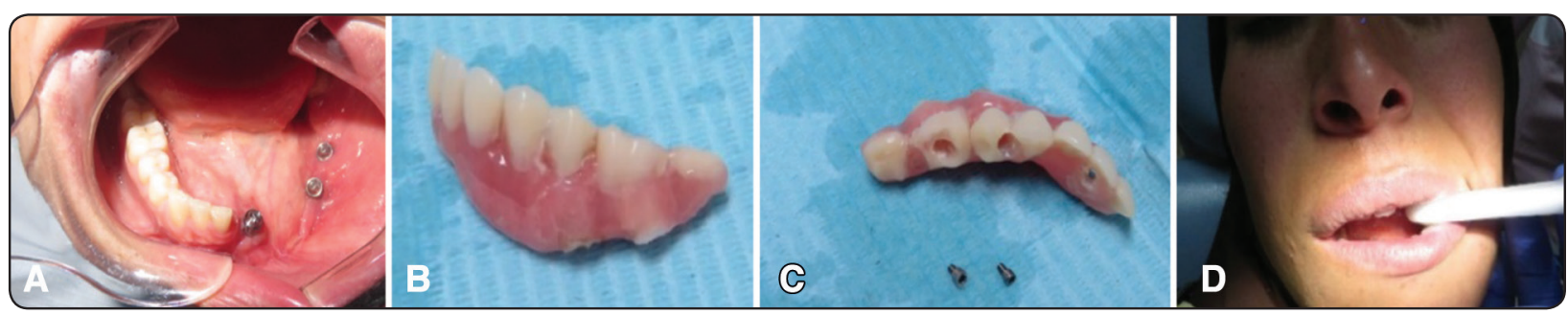

Fig. (4) a: fixation of multi-unit abutment, b: Provisional prosthesis buccal view, c: provisional restoration occlusal view and screws , d: Maximum bite force registration

measured around dental implants at the loading of the prosthesis, six and 12 months.

3. Facial asymmetry: it was calculated by difference between summation of 4 lines measurements using 5 fixed points on defect side of the face and other side. The fixed points used were the most posterior point on the tragus, lateral canthus of the eye, the most lateral point on the angle of the mouth, pogonion point and most inferior point on the angle of the mandible. The 4 lines were canthus tragus line, tragus angle of the mouth, tragus pogonion and canthus angle of the mandible. The differences between both sides of the face were measured preoperative, postoperative after reconstruction surgery after 2- 4 weeks healing time and after prosthetic rehabilitation.

4. Maximum Biting force: To measure the maximum bite force, Patients were seated in an upright position in the dental chair and instructed to bite on the force transducer bite sensor device (occlusal force - meter, GM10, Nagano Kieki.,LTD) was placed on the occlusal surface of the mandibular artificial premolar- molar in the rehabilitated (defect) side. Likewise, in the normal (contralateral) side, it was positioned on the mandibular natural premolar-molar area. Then, each patient was instructed to bite as much as they could on the bite gauge with 45 seconds intervals between biting on each side. The procedure was repeated three times for each side in each patient, and the maximum value of the bite force (MBF) was recorded for each side in newtons $(\mathrm{N})$. (figure $4 \mathrm{~d}$ ). The readings were recorded immediately at the day of loading (0 months), after six months and after 12 months. The Mean maximum biting force for two sides was calculated and compared in a split-mouth designed study between rehabilitated side and normal side.

5. Patient satisfaction and oral health quality of life (OHRQoL): Patient satisfaction was evaluated using an Arabic version of the OHIP-5 (oral health impact profile) questionnaire read to the patient. ${ }^{22}$ All patients were assessed after first stage surgery, at loading of the prosthesis, after six months then after 12 months. This questionnaire includes five domains about functional limitation, pain, psychological discomfort, physical disability, and handicap. The items of the OHIP-5 assessed were the frequency of difficulty chewing, painful aching, uncomfortable about appearance, less flavor in food and difficulty doing usual jobs. Each item was measured on an ordinal rating scale from 0 to 4 : where 0 "never," 1 "hardly ever," 2 "occasionally," 3 "fairly often," 4 "very often." and the sum of the scores for the OHIP-5 scale is between 0 and 20 . A higher score demonstrates inferior OHRQoL and patient satisfaction.

Recorded data was analyzed using the statistical package for social sciences, SPSS version 20.0 (SPSS Inc., Chicago, Illinois, USA). Quantitative data were expressed as mean \pm standard deviation (SD). Qualitative data were expressed as frequency and percentage. A paired T-test was used to compare between both sides. The ANOVA test was used for repeated measures whether there are any differences 
between related measures mean. Post Hoc test: Least Significant Difference (LSD) was used for multiple comparisons between different variables.

\section{RESULTS}

In the current study eleven cases were selected their age, gender and lesions are presented in table 1 .

There were 2 cases presented with failure of grafts and they were subjected to surgical operation for grafting were repeated 6 months later. The complications reported from iliac donor site included persistent pain for 15 days. No post-operative infection, gait disturbances or seroma reported.

Evaluation of bone loss of graft height after 6 months before loading ranged from 1-4 mm (mean $2.14 \pm 1.03)$.

Thirty implants were inserted in 11 patients, 3 implants failed (10\%) with success rate $90 \%$. Marginal bone loss around dental implants was recorded at the time of loading, after six months and after 12 months of loading is presented in table 2 . TABLE (1) Patients age, gender and lesions
There was a statistically significant increase in the peri-implant marginal bone loss along the study period $(\mathrm{P}<0.001)$. table $(2)$

Facial asymmetry reported before surgery, after surgical reconstruction and after prosthetic rehabilitation indicated a statistically significant difference between records $(p<0.0001)$. Means and standard deviation of facial asymmetry measures were presented in table (3)

The maximum biting force of the rehabilitated side was $55.54 \pm 5.22,74.18 \pm 4.35,96.82 \pm 3.65$ at loading time, 6 and 12 months later respectively. An ANOVA test was done to evaluate the effect of time on the maximum biting force of the patient in the rehabilitated side. There was a statistically significant difference $(\mathrm{P}$-value $<0.05)$ in the values of maximum biting force of the rehabilitated side along the study period as shown in Table (4). In a split - mouth designed study, a paired t-test was done to compare the between the maximum biting force of the rehabilitated side and the normal side. There was statistically significant difference between the maximum biting force of the rehabilitated side and

\begin{tabular}{|c|c|c|c|c|c|}
\hline Age & Gender & Ameloblastoma & Residual cyst & $\begin{array}{c}\text { Odontogenic } \\
\text { Keratocyst }\end{array}$ & Myxoma \\
\hline $18-57$ mean & 4 males 36.3\% & $\mathrm{n}=6$ & $\mathrm{n}=2$ & $\mathrm{n}=2$ & $\mathrm{n}=1$ \\
$31.82 \pm 12.12$ & 7 females $63.7 \%$ & $54.5 \%$ & $18.2 \%$ & $18.2 \%$ & $9.1 \%$ \\
\hline
\end{tabular}

TABLE (2) Marginal bone loss around dental implants

\begin{tabular}{|l|c|c|c|c|}
\hline $\begin{array}{l}\text { Marginal bone loss around dental } \\
\text { implants mm }\end{array}$ & Range & Mean & $\begin{array}{c}\text { Repeated Measures } \\
\text { ANOVA }\end{array}$ & p-value \\
\hline At loading & $0.2-2$ & $0.79 \pm 0.47$ & \multirow{2}{*}{204.395} & \multirow{2}{*}{$<0.001^{* *}$} \\
\cline { 1 - 3 } 6 months after loading & $0.5-2.2$ & $1.20 \pm 0.40 \mathrm{a}$ & & \\
\hline
\end{tabular}

TABLE (3) Facial asymmetry reported by difference in measures between both sides

\begin{tabular}{|c|c|c|c|c|c|}
\hline Facial asymmetry & $\begin{array}{c}\text { Before surgery } \\
(\boldsymbol{n}=\mathbf{1 1})\end{array}$ & $\begin{array}{c}\text { After Surgery } \\
(\boldsymbol{n}=\mathbf{1 1})\end{array}$ & $\begin{array}{c}\text { After prosthetic } \\
\text { rehabilitation } \\
(\boldsymbol{n}=\mathbf{1 1})\end{array}$ & $\begin{array}{c}\text { Repeated } \\
\text { Measures } \\
\text { ANOVA }\end{array}$ & p-value \\
\hline Range & $1-3$ & $0.4-1.2$ & $0-0,9$ & \multirow{2}{*}{36.699} & $<0.0001 * *$ \\
\hline Mean \pm SD & $1.7818 \pm 0.5437$ & $1.2818 \pm 1.5899$ & $0.3455 \pm 0.2622$ & & $<$ \\
\hline
\end{tabular}


normal side at loading and at follow up visits ( 6 and 12 months) (P-value <0.05) as shown in Table (5). The difference between the maximum biting force of the rehabilitated and normal sides was decreasing over time as shown in the box chart in figure (5).

ANOVA test was done to compare the scores of OHIP-5 questionnaire (after the first stage surgery, at loading, 6 and 12 months) in each item separately. There was a statistically high significant difference between the scores of all OHIP-5 items scores except in the scores of the difficulty doing jobs item. The latter scores showed a statistically insignificant difference starting form first surgery till 12 months following the loading of the prosthesis. A stock Chart was done showing an obvious decrease in OHIP-5 items scores from the first stage surgery time till 12 months following the loading of the prosthesis which indicates an improvement in the patients' satisfaction and better quality of life. (table 6 and figure 6)

TABLE (4) Maximum biting forces of the Rehabilitated (defect) side in newtons (N)

\begin{tabular}{|c|c|c|c|c|}
\hline Maximum biting force & $\begin{array}{c}\text { At loading } \\
(\boldsymbol{n}=\mathbf{1 1})\end{array}$ & $\begin{array}{c}\text { After 6 } \mathbf{~} \\
(\boldsymbol{n}=\mathbf{1 1})\end{array}$ & $\begin{array}{c}\text { After 12 } \mathbf{~} \\
(\boldsymbol{n}=\mathbf{1 1})\end{array}$ & p-value \\
\hline Rehabilitated side & & & & \\
\hline Range & $49-65$ & $67-80$ & $90-103$ & $<0.05$ \\
\hline Mean \pm SD & $55.54 \pm 5.22$ & $74.18 \pm 4.35$ & $96.82 \pm 3.65$ & \\
\hline
\end{tabular}

able (5) comparison of the maximum biting forces between rehabilitated and normal sides

\begin{tabular}{|l|c|c|c|c|c|c|}
\hline & \multicolumn{2}{|c|}{ At loading (n=11) } & \multicolumn{2}{c|}{ After 6 m $(\boldsymbol{n}=11)$} & \multicolumn{2}{c|}{ After 12 (n=11) } \\
\hline & Rehabilitated side & Normal Side & Rehabilitated side & Normal side & Rehabilitated side & Normal side \\
\hline Mean \pm SD & $55.54 \pm 5.22$ & $101.72 \pm 6.77$ & $74.18 \pm 4.35$ & $110.36 \pm 9.309$ & $96.82 \pm 3.65$ & $114.36 \pm 8.65$ \\
\hline p-value & $<0.05$ & \multicolumn{2}{|c|}{$<0.05$} & \multicolumn{2}{c|}{$<0.05$} \\
\hline
\end{tabular}

\section{$P$-value $\leq 0.05$ was considered significant}

Table (6) OHIP-5 items scores of the study group

\begin{tabular}{|c|c|c|c|c|c|c|}
\hline OHIP-5 & $\begin{array}{c}\text { After first } \\
\text { stage surgery } \\
\quad(n=11)\end{array}$ & $\begin{array}{c}\text { After } \\
\text { Loading } \\
(n=11)\end{array}$ & $\begin{array}{l}6 \text { months } \\
\text { after loading } \\
(n=11)\end{array}$ & $\begin{array}{l}12 \text { months } \\
\text { after loading } \\
(n=11)\end{array}$ & $\begin{array}{l}\text { Repeated } \\
\text { Measures } \\
\text { ANOVA }\end{array}$ & p-value \\
\hline $\begin{array}{l}\text { Difficulty chewing } \\
\text { Range } \\
\text { Mean } \pm \text { SD }\end{array}$ & $\begin{array}{c}2-4 \\
3.81 \pm 0.54\end{array}$ & $\begin{array}{c}2-4 \\
3.63 \pm 0.65\end{array}$ & $\begin{array}{c}0-2 \\
1.00 \pm 0.89\end{array}$ & $\begin{array}{c}0-2 \\
0.82 \pm 0.75\end{array}$ & 320.000 & $<0.001 * *$ \\
\hline $\begin{array}{l}\text { Painful aching } \\
\text { Range } \\
\text { Mean } \pm \text { SD }\end{array}$ & $\begin{array}{c}2-4 \\
2.82 \pm 0.75 \\
\end{array}$ & $\begin{array}{c}1-3 \\
2.45 \pm 0.69 \\
\end{array}$ & $\begin{array}{c}0-2 \\
0.55 \pm 0.69 \\
\end{array}$ & $\begin{array}{c}0-1 \\
0.45 \pm 0.52 \\
\end{array}$ & 165.313 & $<0.001 * *$ \\
\hline $\begin{array}{l}\text { Uncomfortable about appe } \\
\text { Range } \\
\text { Mean } \pm \text { SD }\end{array}$ & $\begin{array}{l}\text { ance } \\
\qquad \begin{array}{c}2-4 \\
3.54 \pm 0.90\end{array} \\
\end{array}$ & $\begin{array}{c}0-2 \\
0.91 \pm 0.70\end{array}$ & $\begin{array}{c}0-1 \\
0.55 \pm 0.52 \\
\end{array}$ & $\begin{array}{c}0-1 \\
0.55 \pm 0.52 \\
\end{array}$ & 149.211 & $<0.001 * *$ \\
\hline $\begin{array}{l}\text { Less flavor in food } \\
\text { Range } \\
\text { Mean } \pm \text { SD }\end{array}$ & $\begin{array}{c}0-3 \\
1.36 \pm 0.81\end{array}$ & $\begin{array}{c}0-2 \\
0.73 \pm 0.65\end{array}$ & $\begin{array}{c}0-2 \\
0.55 \pm 0.69\end{array}$ & $\begin{array}{c}0-1 \\
0.45 \pm 0.52\end{array}$ & 34.000 & $<0.001 * *$ \\
\hline $\begin{array}{l}\text { Difficulty doing usual jobs } \\
\text { Range } \\
\text { Mean } \pm \text { SD }\end{array}$ & $\begin{array}{c}0-2 \\
0.82 \pm 0.75 \\
\end{array}$ & $\begin{array}{c}0-1 \\
0.64 \pm 0.50\end{array}$ & $\begin{array}{c}0-1 \\
0.45 \pm 0.52 \\
\end{array}$ & $\begin{array}{c}0-1 \\
0.36 \pm 0.50\end{array}$ & 2.251 & 0.164 \\
\hline
\end{tabular}




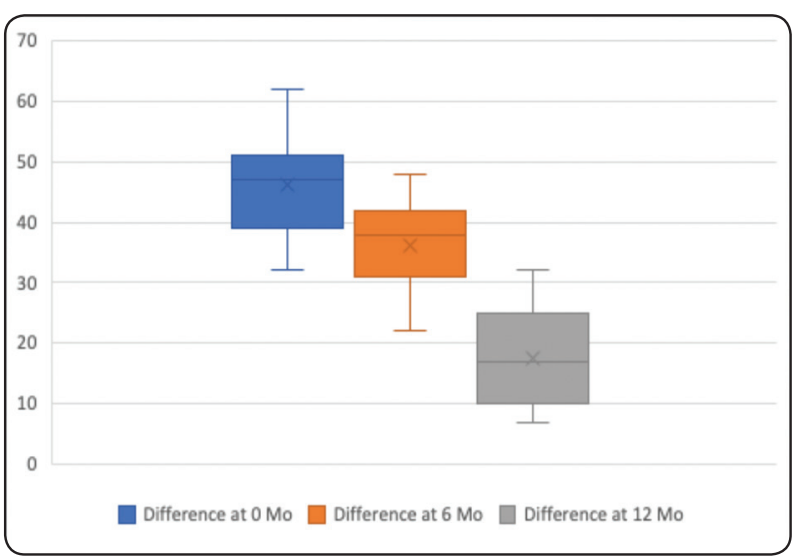

Fig. (5) Box chart showing The difference in biting forces between both sides at loading time, after 6 and 12 months.

\section{DISCUSSION}

It is widely accepted that immediate reconstruction may be performed without risk for a delayed diagnosis of recurrent diseases. Numerous studies reported the surgical outcome regarding success rate and complications of osseointegrated implants following mandibular reconstruction. Delayed reconstruction was critical to allow maturation of the wound bed for nonvascular bone grafting. Success could be defined as restoration of bone continuity and complete consolidation with absence of infection both clinically and radiographically. Immediate reconstruction combined with implant placement was investigated with free vascularized grafts with a good success rate. A few reports in the literature regarding the iliac crest free grafts combined with dental implants. In the current study immediate reconstruction using free non vascularized iliac grafts combined with implant placement was performed in 11 patients, failure of grafts was reported into 2 patients $18 \%$ due to recurrence. Kruger et al. reported graft loss rate of $20 \%$ after immediate grafting, Komisar et al. reported graft loss of 3.2\% for delayed grafting and $28.5 \%$ in immediate bone grafts, Lawson et al. reported success rates of delayed and immediate grafting to be $91 \%$ and $46 \%$ respectively.$^{23-26}$

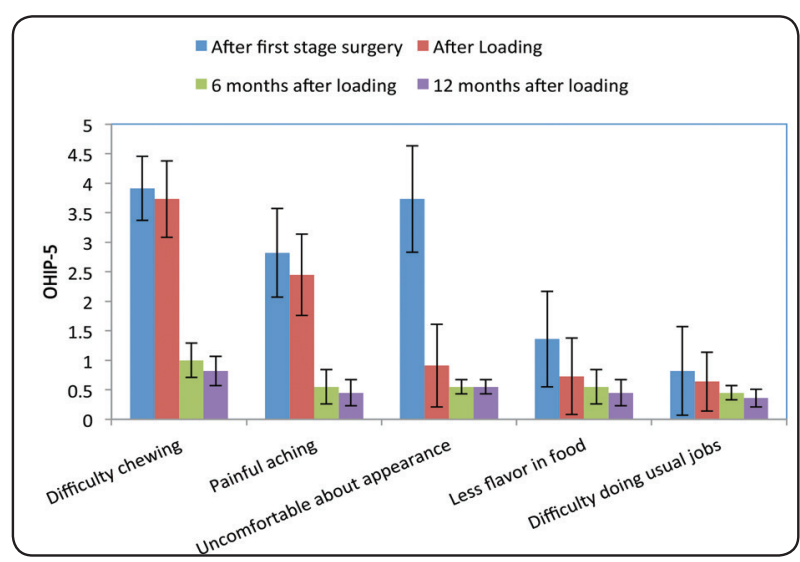

Fig. (6) Stock chart showing the extent of the difference over the periods through OHIP-5 of the study group.

A direct comparison of non-vascularized with vascularized bone grafts in 75 consecutive reconstructions by Foster et al reported a rate of bony union in $69 \%$ of Non-vascularized bone grafts versus $96 \%$ of vascularized grafts. It was stated Non-vascularized bone grafts may best be suited for reconstruction of small defects $(<6 \mathrm{~cm})$ in patients who will not tolerate major surgery. In the same study it was reported Overall implant success: $82 \%$ $(27 / 33)$ in non-vascularized bone grafts versus $99 \%(70 / 71)$ in vascularized bone grafts. However recently grafting combined with implant placement was reported in higher success rate which in accordance with the results of the current study as Zou et al. reported $100 \%$ survival rate of the bone grafts during the follow-up period. The success rates of implants placed in the reconstructed areas in vascularized calvarial or iliac bone grafts were $96.7 \%$ and $93.3 \%$, respectively, in a 9-year retrospective study. other recent study reported $96.4 \%$ and $91.8 \%$ survival rate in immediate implant with grafts or delayed protocol, however free vascularized grafts where used in both studies. ${ }^{27,28}$

In the current study the success rate was $90 \%$ of dental implants in free non vascularized iliac crest grafts. The success of implant surgery, aesthetically and functionally depends on the amount of bone and gingival tissues support around dental implants. In 
the current study dental implants were inserted in at the time of grafting in a free non vascularized iliac crest graft and the success rate was $90 \%$ and mean marginal bone resorption was $1.42 \pm 0.38$ after 12 months of loading. They coincide with the results reported by Pappalardo et al. as the marginal bone loss around the implants in patients with mandibular ameloblastoma treated with segmental resection and vascularized fibula flap reconstruction, was less than $1.5 \mathrm{~mm}$ during the follow-up period between 6 to 20 months. $^{29}$

Several factors contributed to the success rate of dental implants in non-vascularized iliac crest grafts; the size of mandibular defect, preservation of the inferior border of the mandible, the time of ischemia of the bone graft from utilization till fixation and the primary implant stability. In the current study, the primary stability was minimum $25 \mathrm{~N} / \mathrm{cm}$ and the implants were anchored through the graft and recipient basal bone. ${ }^{30}$

In this study, a provisional fixed-detachable (screw-retained) prosthesis was selected as it provides advantages of both fixed and removable prosthesis. It provides better esthetics derived from its acrylic part compensating for bone loss in the defect side and can be retrieved by the prosthodontist for better hygiene maintenance. Additionally, it can reduce dynamic forces from occlusal load on bone graft and implants until complete consolidation of the graft. ${ }^{31}$ Also, after the osseointegration of implants period, a provisional implant-retained prosthesis can be constructed to allow soft-tissue contouring, providing a provisional view of load distribution, function, esthetics and determining the design of the definitive prosthesis afterwards The outcomes in this study regarding success of rehabilitation and reconstruction of mandibular defects within implants in bone graft and hybrid prosthesis were similar to recent studies which concluded that implants in bone grafts and implantsupported prostheses seem to have better effect on bone resorption, possibly because prosthetic load induces the graft and prevents bone resorption. ${ }^{32,33}$
Maximum bite force in mandibular defect patients rehabilitated with iliac bone graft and implant supported prosthesis can be an indication of the masticatory efficiency of this prothesis. Assessing the bite force and masticatory outcome of this time -consuming and demanding treatment option is important for their evaluation and acceptance as treatment modality. Enhancement of the masticatory efficiency and bite force is one of the chief reasons why patients seek dental rehabilitation. ${ }^{34,35}$

There is a lack of evidence on the effect of rehabilitation on the masticatory performance in patients with reconstructed mandibles using implant-retained prosthesis. Accordingly, this lack of evidence leads to a questionability of the benefits of this treatment modality. ${ }^{21}$ Few researches were conducted to evaluate the biting force of the implantretained prostheses in reconstructed mandibular defects. Most of them evaluated and compared biting force of rehabilitated side and normal side at a specific time after treatment. ${ }^{36}$ The effect of time on the biting force in the rehabilitated side in reconstructed mandible is not fully understood. Also, the difference between the maximum biting force of the rehabilitated side and the normal side in reconstructed mandible during the first year was not elaborated.

In the current study, there was a statistically significant difference in the maximum biting force of the rehabilitated side at loading, 6 and 12 months. There was a significant increase in the maximum biting force of the rehabilitated side over the first year. It can be attributed to the increasing confidence of the patient and muscle control over time to masticate and function using the rehabilitated side. There was a significant difference between the maximum biting force in the normal and rehabilitated side at loading, 6 and 12 months follow ups, which is a predictable and logic finding may be owing to history of the defect in the patient, fear of masticating on this side and better muscle control on the normal side. 
This outcome is different from the results of a similar study which concluded that there was no difference between masticatory efficiency of the normal side and rehabilitated side in reconstructed mandible. ${ }^{36}$ This contradiction may be due to the fact the measured the masticatory efficiency was after a three years period and not during the first year of prothesis loading. Despite this significant difference between the biting force of rehabilitated and normal side in this research, there was an obvious decrease in the difference from loading time to 6 and 12 months follow ups. It can be attributed to the improving muscle control of the rehabilitated side and increasing confidence of the patients to use this side. According to this outcome it can be predicted that the biting force of the patients with rehabilitated mandibular defect with iliac crest and implant-assisted prosthesis can regain the biting force of the defect side after the first year of loading.

Oral lesions may lead to facial asymmetry, pain, speech problems, and malocclusion. The ideal treatment should achieve adequate excision minimizing recurrence, provide excellent cosmesis, and restore oral functions to allow a higher quality of life. In the current study facial asymmetry was evaluated after reconstruction surgery and after prosthetic rehabilitation in regard to the preoperative findings and it was obvious that facial asymmetry was improved after reconstruction surgery and improved more after prosthetic rehabilitation and these findings were in accordance with the oral health quality of life assessment results. As the immediate reconstruction will improve the patient esthetic and function in addition to combined implant placement. It will improve the patient satisfaction as well as reduced treatment time and number of surgeries.

Perceptions of patients about the difficulty in speech, esthetics and function can lead to depression and social isolation. ${ }^{37}$ Consequently, prosthetic rehabilitation plays an essential role in the perceptions of patients with reconstructed mandibular defects and their oral health related to quality of life. ${ }^{38}$ The patients' satisfaction is a chief outcome and a critical point in determining the success of any treatment option. Few studies of the patients' satisfaction and perception of treatment options in reconstructed mandibular defects with bone graft and implant retained prosthesis are available. ${ }^{39}$

The oral health quality of life of the patient in this study was evaluated by an Arabic version of OHIP-5 questionnaire which is a reliable, validated and feasible method of to assess patents, satisfaction with dental rehabilitation. ${ }^{22}$ Patients' sores were assessed after the first surgery, at loading of the prosthesis, 6 and 12 after loading. The results showed a significant difference and decrease between patient scores in every item of the OHIP-5 questionnaire at different follow up recalls at the first surgery, loading, 6 and 12 months except in the difficulty doing usual jobs item scores. This decrease in the scores indicates improvement in patients' satisfaction and oral health quality of life.

The results of this study regarding patients' satisfaction was in agreement with other similar studies ${ }^{40,29}$ The difficulty doing usual jobs item scores did not show a significant decrease which can be attributed to the inclusion criteria of the study. The patients selected had unilateral mandibular defect not crossing mandible midline and not invading inferior border of the mandible. Therefore, marginal resection was done which is less aggressive and more conservative surgical treatment providing better functional levels. Consequently, the patients in this study did not have difficulty in doing normal jobs from the first stage surgery till the end of the study period (12 months following the loading of the prosthesis).

\section{CONCLUSION}

Within the limitations of this study, it was concluded that reconstruction of mandibular defect using iliac crest graft combined with dental implants and retaining a provisional fixed-detachable prothesis can be an effective procedure to restore bony defect, maximum bite force, facial symmetry, patient satisfaction and oral health quality of life. 


\section{REFERENCES}

1. Kumar BP, Venkatesh V, Kumar KA, Yadav BY, Mohan SR: Mandibular Reconstruction: Overview. J. Maxillofac. Oral Surg. 2016; 15(4):425-441

2. Neville BW, Damn DD, Allen CM, Bouqout JE, editors. Oral and maxilla facial pathology. 2nd ed. Philadelphia: WB Saunders Co; 2002:610-5.

3. Bucci T, Nocini PF: Functional Reconstruction of Nonsegmental Mandibular Defect with Fresh Frozen Bone Graft and Delayed Implants Placement. J Craniofac Surg 2017;28: 810-812

4. Neligan PC. Head and neck reconstruction. Plast Reconstr Surg 2013; 131:260e-269e.

5. Freier K, Mertens C, Engel M, Hoffmann J. Therapeutic strategies for the reconstruction of extensive mandibular defects. HNO 2013; 61:551-558.

6. Shen YF, Rodriguez ED, Wei FC, et al. Aesthetic and functional mandibular reconstruction with immediate dental implants in a free fibular flap and a low-profile reconstruction plate: fiveyear follow-up. Ann Plast Surg, 2015;74(4):442-6.

7. Foster RD, Anthony JP, Sharma A, Pogrel MA. Vascularized bone flaps versus non vascularized bone grafts for mandibular reconstruction: an outcome analysis of primary bony union and endosseous implant success. Head Neck 1999;21:66-71.

8. Simon ENM, Merkx MAW, Kalyanyama BM, Shubi FM. Immediate reconstruction of the mandible after resection for aggressive odontogenic tumours: a cohort study. Int J Junior PC, Zanetta-Barbosa D. Immediate loaded implantsupported Oral Maxillofac Surg 2013; 42:106-12.

9. Carneiro TAN, Oliveira MTF, Lima LB, Simamoto- -Junior PC, Zanetta-Barbosa D. Immediate loaded implantsupported prosthesis after mandibular reconstruction with free iliac crest bone graft. Rev Port de Estomato Med Dent e Cir Maxilofac 2015;5 6(2):117-121

10. Chiapasco M, Colletti G, Romeo E, et al. Long-term results of mandibular reconstruction with autogenous bone grafts and oral implants after tumor resection. Clin Oral Implants Res. 2008; 19:1074-80

11. Bidra AS, Veeranki AN. Surgical and prosthodontic reconstruction of a gunshot injury of the mandible using dental implants and an acrylic resin fixed prosthesis: a clinical report. J Prosthet Dent. 2010; 104:142-8
12. Kim A, Kar K, Nowzari H, Cha HS, Ahn KM. Immediate free iliac bone graft after non segmental mandibular resection and delayed implant placement: a case series. Implant Dent. 2013;22:438-43

13. Simon EN, Merkx MA, Kalyanyama BM, Shubi FM, Stoelinga PJ. Immediate reconstruction of the mandible after resection for aggressive odontogenic tumours: a cohort study. Int J Oral Maxillofac Surg 2013; 42:106-112

14. Goiato MC, de Medeiros RA, Vechiato Filho AJ, da Silva EV, Sonego MV, de Carvalho KH, et al. Prosthetic rehabilitation of a patient after a partial mandibulectomy. Ann Med Surg (Lond) 2015; 4:200-3.

15. Yoon HI, Han JS. Prosthetic rehabilitation with an implantsupported fixed prosthesis using computer-aided design and computer-aided manufacturing dental technology for a patient with a mandibulectomy: A clinical report. J Prosthet Dent 2016;115:133-6

16. Munot VK, Nayakar RP, Patil R. Prosthetic Rehabilitation of Mandibular Defects with Fixed-removable Partial Denture Prosthesis Using Precision Attachment: A Twin Case Report Contemp Clin Dent. 2017 Jul-Sep; 8(3): 473-478

17. Jain AR. A prosthetic alternative treatment for severe anterior ridge defect using fixed removable partial denture Andrew's Bar system. World J Dent. 2013; 4:282-5.

18. Cawood JI, Stoelinga PJ. International Academy for Oral and Facial Rehabilitation Consensus Report. Int J Oral Maxillofac Surg. 2006; 35:195-198.

19. GoodacreCJ,BernalG,RungcharassaengK,KanJY.Clinical complications with implants and implant prostheses. J Prosthet Dent. 2003;90:121-132.

20. Petrovic I, Panchal H, De Souza Franca PD, Hernandez M, McCarthy CC, Shah JP. A systematic review of validated tools assessing functional and aesthetic outcomes following fibula free flap reconstruction of the mandible. Head \& Neck. 2019; 41:248-255.

21. Wijbenga JG, Schepers RH, Werker PM, Witjes MJ, Dijkstra PU. A systematic review of functional outcome and quality of life following reconstruction of maxillofacial defects using vascularized free fibula flaps and dental rehabilitation reveals poor data quality. J Plast Reconstr Aesthet Surg. 2016;69(8):1024-36.

22. Alhajj MN, Halboub E, Khalifa N, Amran. A Translation and validation of the Arabic version of the 5-item Oral health impact profile: OHIP Health and Quality of Life Outcome 2018; 16:218. 
23. Julide Ozen, Behcet Erol, Sibel Dikicier, Gulce Alp, Rehabilitation With an Implant-Supported Metal-Acrylic Fixed Prosthesis After Ameloblastoma Resection in Mandible: Clinical Case Letter, Journal of Oral Implantology. 2017;43(5):365-369.

24. Krüger E, Krumholz K. Results of bone grafting after rigid fixation. Journal of Oral and Maxillofacial Surgery. 1984; 42: 491-6.

25. Komisar A, Warman S \& Danziger E: A critical analysis of immediate and delayed mandibular reconstruction using A-O plates. Archives of Otolaryngology - Head and Neck Surgery. 1989; 115: 830-3.

26. Lawson W \& Biller HF: Mandibular reconstruction: bone graft techniques. Otolaryngology -Head and Neck Surgery. 1982; 90: 589-94.

27. Foster RD, Anthony JP, Sharma A, Pogrel MA Vascularized bone flaps versus nonvascularized bone grafts for mandibular reconstruction: an outcome analysis of primary bony union and endosseous implant success. Head Neck, 1999;21(1):66-71

28. Zou D, Huang W, Wang F, Wang S, Zhang Z, Zhang C, Kaigler D, Wu Y. Autologous Ilium Grafts: Long-Term Results on Immediate or Staged Functional Rehabilitation of Mandibular Segmental Defects Using Dental Implants after Tumor Resection. Clinical Implant Dentistry and Related Research, 2015;17, (4) 779-89.

29. Pappalardo M, Tsao CK, Tsang ML, Zheng J, Chang YM, Tsa CY: Long-term outcome of patients with or without osseointegrated implants after resection of mandibular ameloblastoma and reconstruction with vascularized bone graft: Functional assessment and quality of life. J. plastic of Reconstructive \& Aesthetic Surgery 2018; 71, 1076-1085.

30. Likhterov I, Roche AM, Urken ML. Contemporary Osseous Reconstruction of the Mandible and the Maxilla. Oral Maxillofac Surg Clin North Am. 2019;31(1):101-116.

31. Misch CE. Contemporary Implant Dentistry. 3rd ed. St. Louis, MO: Mosby Elsevier; 2008:99-100.

32. Montero J, de Paula CM, Albaladejo A. The "Toronto prosthesis", an appealing method for restoring patients' candidates for hybrid overdentures: a case report. J Clin Exp Dent. 2012;4: e309-e312.

33. Kurt M, Bal BT, Uraz A, Kahraman S Multidisciplinary rehabilitation of eosinophilic granuloma with bone graft surgery and a modified implant-supported hybrid prosthesis: A case report with a 6-year follow-up Special Care in Dentistry; 2019, 39 (1) : 45 - 50

34. Roumanas ED, Garrett N, Blackwell KE, Freymiller E, Abemayor E, Wong WK, Kapur KK Masticatory and swallowing threshold performances with conventional and implant-supported prostheses after mandibular fibula freeflap reconstruction. Journal of Prosthetic Dentistry; 2006 96, 289-297

35. Fueki, K., Kimoto, K., Ogawa, T., \& Garrett, N. R. Effect of implant-supported or retained dentures on masticatory performance: A systematic review. Journal of Prosthetic Dentistry; 2007. 98, 470-477

36. Kumar VV, Srinivasan M: Masticatory efficiency of implant-supported removable partial dental prostheses in patients with free fibula flap reconstructed mandibles: A split-mouth, observational study. Clinical Oral Implants Research, ISSN 0905-7161, 08/2018, Volume 29, Issue 8, pp. $855-863$

37. Kashbour WA, Rousseau NS, Ellis JS, Thomason JM. Patients' experiences of dental implant treatment: A literature review of key qualitative studies. J Dent 2015; 43:789-97

38. Mericske-Stern R, Perren R, Raveh J. Life table analysis and clinical evaluation of oral implants supporting prostheses after resection of malignant tumors. Int J Oral Maxillofac Implants 1999; 14:673-80.

39. Aimaijiang Y, Otomaru T, Taniguchi H. Relationships between perceived chewing ability, objective masticatory function and oral health-related quality of life in mandibulectomy or glossectomy patients with a dento-maxillary prosthesis. J Prosthodont Res 2016; 60:92-7.

40. Karayazgan-Saracoglu B, DDS, Atay A, Korkmaz C, and Gunay Y Quality of life assessment of implant-retained overdentures and fixed metal-acrylic resin prostheses in patients with marginal mandibulectomy J Prosthet Dent 2017; 118:551-560 